Kyoto University,

Graduate School of Economics

Research Project Center Discussion Paper Series

The Importance of the Retention Ratio in a Kaleckian Model with Debt Accumulation

Hiroaki Sasaki and Shinya Fujita

Discussion Paper No. E-10-008

Research Project Center

Graduate School of Economics

Kyoto University

Yoshida-Hommachi, Sakyo-ku

Kyoto City, 606-8501, Japan

November 2010 


\title{
The Importance of the Retention Ratio in a Kaleckian Model with Debt Accumulation
}

\author{
Hiroaki SASAKI ${ }^{\dagger}$ and Shinya FUJTA ${ }^{\ddagger}$
}

\begin{abstract}
Hein (2007) investigates the effects of debt of firms and interest rates on output and growth, and obtains the following three results. First, the long-run equilibrium is stable only if the short-run equilibrium is debt-led growth. Second, to obtain a positive long-run equilibrium value of the debt-capital ratio under the debt-led growth regime, extremely high interest rates are necessary. Third, the long-run equilibrium value of the rate of capital accumulation is increasing in interest rates and is independent of income distribution. However, these conclusions depend crucially on the assumption that the retention ratio of firms is equal to unity, and hence, that there is no dividend to shareholders. By relaxing the above assumption, we show in this paper that even the long-run equilibrium under the debt-burdened growth regime can be stable and that the long-run equilibrium value of the debt-capital ratio will be positive with plausible interest rates irrespective of whether the long-run equilibrium is debt-led growth or debt-burdened growth. Moreover, the effects of interest rates and income distribution on capital accumulation differ from regime to regime.
\end{abstract}

\section{Introduction}

While many post-Keynesian researchers debate the relationship between income distribution and economic growth, some Kaleckian researchers have investigated the link between debt accumulation and economic growth. The economy is termed debt-led if increases in the debt-capital ratio and the interest rate raise the rate of capacity utilization and/or the rate of capital accumulation. The economy is correspondingly termed debt-burdened if increases in the debt-capital ratio and the

\footnotetext{
+ Graduate School of Economics, Kyoto University. E-mail: sasaki@econ.kyoto-u.ac.jp

* Graduate School of Economics, Nagoya University. E-mail: fujita@soec.nagoya-u.ac.jp
} 
interest rate lower the rate of capacity utilization and/or the rate of capital accumulation. Models that consider the effect of debt-accumulation on economic growth include Taylor (2004, ch. 8), Lima and Meirelles (2007), and Charles (2008a, 2008b). ${ }^{1}$ Taylor (2004, ch. 8) introduces the effect of interest payments into the investment function and shows the possibility of debt-led and debt-burdened regimes. In addition, he shows that the effect of fiscal expenditure depends on the regime. Both Lima and Meirelles (2007) and Charles (2008a, 2008b) introduce a Minskyan taxonomy with regard to the financial fragility of the economy into Kaleckian models that consider debt-accumulation. However, Lima and Meirelles's model assumes that the savings rate of capitalists is equal to the retention ratio of firms. Accordingly, their model economy is neither debt-led nor debt-burdened. Charles's model assumes that firms' investment depends only on their retained profits, whereas in the usual Kaleckian models, investment depends on the rate of capacity utilization and on interest payments. Consequently, capital accumulation in Charles's model necessarily leads to debt-burdened.

Lavoie (1995) and Hein (2007) can be characterized as benchmark models of the "monetary theory of production" in that they clearly investigate the effects of monetary variables such as interest rates and the debt-capital ratio on real variables such as capacity utilization and capital accumulation. While Lavoie (1995) assumes that investment is exogenously given, Hein (2007) considers a Kaleckian investment function with a negative effect of interest payments, which is also adopted in Taylor (2004). In the short run of these models, disequilibrium of the goods market is adjusted through changes in capacity utilization with the debt-capital ratio remaining constant.

1 The following are Kaleckian models that consider financial factors. Asada (2006) presents a kind of Kaleckian model that considers debt-accumulation and analytically shows the existence of cyclical fluctuations. Charles (2010) presents a Kaleckian model in which firms' propensity to invest changes endogenously and shows the occurrence of chaotic dynamics in a relatively simple framework. However, his result depends crucially on the assumption that time is discrete. Hein (2010) presents a model in which the outside finance-capital ratio is an endogenous variable; the fundamental structure of the model is the same as that of Hein (2007). For Hein (2010), see also the empirical study of Hein and van Treeck (2010). Setterfield (2009) introduces a monetary policy termed the Pasinetti rule and investigates the effect of the policy. 
Lavoie and Hein analyze how increases in the debt-capital ratio and interest rates affect the rates of capacity utilization and capital accumulation. In the long run, the goods market always clears and the debt-capital ratio becomes an endogenous variable. Hein (2007) finds that, if the short-run equilibrium rate of capital accumulation is debt-led, the long-run dynamics of the debt-capital ratio are always stable. In contrast, if the short-run equilibrium rate of capital accumulation is debt-burdened, the long-run dynamics are always unstable.

However, Hein's result that the long-run dynamics of the debt-capital ratio are stable only if the short-run equilibrium is debt-led growth is questionable from an empirical standpoint. For example, Hein and Schoder (2009) empirically study the effect of the debt-capital ratio on the rate of capacity utilization in the US and Germany, and show that both countries are debt-burdened. It is implausible that the debt-capital ratio of these debt-burdened economies diverges to infinity.

In addition, in Hein (2007), extremely high interest rates are needed to obtain a positive long-run equilibrium value of the debt-capital ratio under the stable debt-led growth regime. Hein and Schoder (2009) estimate parameters of the investment function, from which we can deduce that unless interest rates are kept at $8 \%$ in the US and $20 \%$ in Germany, the equilibrium debt-capital ratio of Hein (2007) will be negative.

Moreover, in Hein (2007), the long-run equilibrium rate of capital accumulation leads to the product of the savings rate of financial capitalists and the rate of interest. From this, it follows that the paradox of thrift does not hold and that an increase in the rate of interest leads to a rise in the rate of capital accumulation, which contradicts the usual Keynesian intuition.

In this paper, we show that Hein's results depend crucially on the assumption that the retention ratio of firms is equal to unity, and hence, that there are no dividend payments to shareholders. Indeed, if this assumption is relaxed - that is, if the retention ratio of firms is less than unity - the long-run equilibrium will be stable even if the short-run equilibrium is debt-burdened. In addition, under this relaxed assumption, the long-run equilibrium value of the debt-capital ratio will be positive with plausible 
interest rates irrespective of whether the economy is debt-led or debt-burdened growth. Moreover, the effects of interest rates and income distribution and interest rates on capital accumulation differ from regime to regime.

The remainder of the paper is organized as follows. Section 2 briefly explains the structure of Hein's (2007) model and shows its drawbacks. Section 3 presents our modified model, in which the retention ratio of firms is strictly less than unity and shows some analytical results. Section 4 presents some numerical examples to ascertain the results of the previous section and to clarify those aspects that cannot be known analytically. Section 5 concludes the paper.

\section{The basic structure of Hein's (2007) model}

This section surveys the basic structure of Hein's (2007) model and shows some special results that arise from the assumption that the retention ratio is equal to unity.

We assume a closed economy without government. There exists a single good, which can be used for both production and consumption. Technological progress is not explicitly considered: both the potential output-capital ratio and the output-labor ratio are assumed to be constant. There are three agents in our economy: firms with excess capacity, workers, and financial capitalists. Firms invest without issuing new shares, using a part of profits and external funds that are financed by capitalists via banks, which in turn set the nominal loan rate (interest rate).

The profit rate $(r)$ is defined as the nominal profit $(\Pi)$ divided by the price level $(p)$ and the existing capital stock $(K)$.

$$
r \equiv \frac{\Pi}{p K}=\frac{\Pi}{p Y} \frac{Y}{\bar{Y}} \frac{\bar{Y}}{K}=\frac{h}{v} u, h \in(0,1),
$$

where $Y$ denotes real output and $\bar{Y}$ denotes potential output. The rate of profit is composed of three factors: the profit share $(h)$, the rate of capacity utilization $(u=Y / \bar{Y})$, and the potential output-capital ratio $(v=\bar{Y} / K){ }^{2}$ In the following

${ }^{2}$ Hein (2007) considers the case where the mark-up rate in the price equation elastically changes according to the interest rate. However, we abstract from this case because such an equation does not change our results very much. 
discussion, we assume $v=1$ for the sake of simplicity.

According to the post-Keynesian "horizontalist" view (Moore (1988), Rochon (1999), and Fontana (2009)), we assume that firms can make use of loans, which are financed by capitalists, under a given nominal interest rate $(i)$. Because firms hold the nominal sock of debt $(L)$, they have to pay interest ( $i L)$ with a dividend to capitalists in each period. Therefore, firms' nominal profits are split into their retained profits $\left(\Pi_{f}\right)$ and the capitalists' income $\left(\Pi_{c}\right)$, which is composed of dividend and interest receipts.

$$
\begin{gathered}
\frac{\Pi_{f}}{p K}=s_{f}\left(\frac{\Pi}{p K}-i \frac{L}{p K}\right)=s_{f}(h u-i \lambda), s_{f} \in(0,1), i>0, \\
\frac{\Pi_{c}}{p K}=\left(1-s_{f}\right)(h u-i \lambda)+i \lambda,
\end{gathered}
$$

where $s_{f}$ denotes the retention ratio, which is assumed to be constant; and $\lambda(\equiv L / p K)$ denotes the debt-capital ratio. The first term of the RHS in Equation (3) represents dividends, and the second term represents interest income.

We assume that capitalists save a constant fraction $\left(s_{f}\right)$ of their income, while workers do not save. Total saving $(S)$ is composed of retained profits and savings from capitalists' incomes. Using Equations (2) and (3), we obtain the aggregate saving function.

$$
\frac{S}{K}=s_{f}(h u-i \lambda)+s_{c}\left[\left(1-s_{f}\right)(h u-i \lambda)+i \lambda\right], s_{c} \in(0,1) .
$$

Firms make an investment plan ( $I$ ), which is given by the following desired investment function:

$$
g \equiv \frac{I}{K}=\alpha+\beta u+\tau h-\theta i \lambda, \alpha>0, \beta>0, \tau>0, \theta>0 .
$$

Equation (5) shows that the rate of capital accumulation ( $g$ ) responds positively to the profit share and the rate of capacity utilization (Bhaduri and Marglin (1990)) and negatively to interest payments per existing capital, $i \lambda$ (Taylor (2004), and Taylor 
and Arnim (2008)). ${ }^{3}$

\subsection{Short-run equilibrium}

In the short run, disequilibrium between investment and saving is adjusted through changes in capacity utilization under given capital and debt stocks.

Hein (2007) assumes that $s_{f}=1$ for the sake of simplicity: firms do not pay a dividend to capitalists. To see what happens in this case, this section accepts the assumption that $s_{f}=1$. The equilibrium rate of capacity utilization is obtained from Equations (4) and (5).

$$
u=\frac{\alpha+\tau h+\left(1-s_{c}-\theta\right) i \lambda}{h-\beta}
$$

This equilibrium will be stable if saving responds more elastically to variations in capacity utilization than investment, that is, if $h-\beta>0$, which we assume in the following discussion.

If the reaction coefficient of investment to interest payments and capitalists' propensity to save are sufficiently small, that is, if $1-s_{c}-\theta>0$, increases in the debt-capital ratio and the interest rate raise the rate of capacity utilization. This case is called the debt-led capacity utilization (DLCU, hereafter) regime in the recent Kaleckian literature. If $1-s_{c}-\theta<0$, then increases in the debt-capital ratio and the interest rate reduce the rate of capital accumulation; this case is called the debt-burdened capacity utilization (DBCU, hereafter) regime.

Substituting Equation (6) in Equation (5), we get the rate of capital accumulation in the short-run equilibrium.

$$
g=\frac{h(\alpha+\tau h)+\left[\beta\left(1-s_{c}\right)-\theta h\right] i \lambda}{h-\beta} .
$$

\footnotetext{
${ }^{3}$ Post-Keynesian models feature many variants of the desired investment function. Hein (2006) uses a normal Kaleckian-type investment function that positively relates investment per capital to the profit rate and the rate of capacity utilization. Charles (2008a, 2008b, 2008c) assumes that investment is an increasing function of retained profits. Under this assumption, capital accumulation is debt-burdened in the short-run equilibrium.
} 
Whether capital accumulation is debt-led or debt-burdened depends on the profit share and the reaction coefficient of investment to the rate of capacity utilization, in addition to the coefficient of interest payment and to the capitalists' savings propensity. If $\beta\left(1-s_{c}\right)-\theta h>0$, then the short-run equilibrium is debt-led growth (DLG, hereafter). If, on the other hand, $\beta\left(1-s_{c}\right)-\theta h<0$, then the short-run equilibrium is debt-burdened growth (DBG, hereafter).

As we have seen, the condition for DLCU (DBCU) differs from the condition for DLG (DBG). Note that DBCU is not compatible with DLG. ${ }^{4}$ Therefore, in Hein (2007), there exist the following three cases for the debt regimes.

Case (a): the short-run equilibrium is both DLCU and DLG.

Case (b): the short-run equilibrium is both DBCU and DBG.

Case (c): the short-run equilibrium is both DLCU and DBG.

\subsection{Long-run equilibrium}

In the long run, the debt-capital ratio becomes an endogenous variable, while the goods market always clears. The growth rate of the debt-capital ratio is given by

$$
\dot{\lambda}=\left(\frac{\dot{L}}{L}-g\right) \lambda=\frac{\dot{L}}{p K}-g \lambda,
$$

where inflation is assumed to be zero. Firms' loans in each period are equal to the difference between total investment and their internal profits. Since the goods market always clears, loans are finally identical with the savings from capitalists' incomes. ${ }^{5}$

4 The condition for DBCU is given by

$$
x \equiv 1-s_{c}-\theta<0 .
$$

The condition for DLG is given by

$$
y \equiv \beta\left(1-s_{c}\right)-\theta h>0 .
$$

Using these two equations, we obtain

$$
y \equiv \beta(x+\theta)-\theta h=\beta x+\theta(\beta-h) .
$$

Here, $x<0$ and $\beta-h<0$ imply $y<0$. Therefore, DBCU necessarily leads to DBG.

${ }^{5}$ If the agents who save out of income are not capitalists but workers, firms' loans are 


$$
\frac{\dot{L}}{p K}=\frac{I}{K}-(h u-i \lambda)=s_{c} i \lambda
$$

Substituting Equation (9) in Equation (8) yields

$$
\dot{\lambda}=\left(s_{c} i-g\right) \lambda \text {. }
$$

The long-run equilibrium debt-capital ratio $\left(\lambda^{*}\right)$ is derived from $\dot{\lambda}=0$ and from Equations (7) and (10).

$$
\lambda^{*}=\frac{s_{c} i(h-\beta)-h(\alpha+\tau h)}{i\left[\beta\left(1-s_{c}\right)-\theta h\right]} .
$$

Here, we abstract a trivial solution, $\lambda^{*}=0$, because it is economically meaningless. In addition, empirical studies by Taylor and Arnim (2008) and Hein and Schoder (2009) show that the debt-capital ratio is positive in advanced capitalistic countries; hence, we assume that $\lambda^{*}>0$.

The long-run equilibrium will be locally stable if the following condition is satisfied.

$$
\frac{\partial \dot{\lambda}}{\partial \lambda}=-\frac{\partial g}{\partial \lambda} \lambda^{*}=-\frac{\left[\beta\left(1-s_{c}\right)-\theta h\right] i}{h-\beta} \lambda^{*}<0 .
$$

Because $h-\beta>0$ and $\lambda^{*}>0$, the necessary and sufficient condition for local stability is given by $\beta\left(1-s_{c}\right)-\theta h>0$. Note that this condition coincides with the condition for DLG. Therefore, we obtain the following result.

Result 1. (Hein, 2007) Suppose that the long-run equilibrium debt-capital ratio is positive. When $s_{f}=1$, the long-run equilibrium is stable (unstable) if the short-run equilibrium is $D L G(D B G)$.

Now, consider the case where the long-run equilibrium is locally stable, in other words, where the short-run equilibrium is DLG (Case (a)). For the positive equilibrium debt-capital ratio, the numerator of the RHS in Equation (11) must be positive (that is, $\left.s_{c} i(h-\beta)-h(\alpha+\tau h)>0\right)$ because its denominator is also positive. This yields

equivalent to workers' savings (Dutt and Amadeo (1993)). 
$i>h(\alpha+\tau h) /\left[s_{c}(h-\beta)\right]$. Therefore, we obtain the following result.

Result 2. (Hein, 2007) To obtain a positive debt-capital ratio in the long-run equilibrium, extremely high interest rates are needed.

For example, suppose that $\alpha=0, s_{c}=1$, and $h=0.3$, and substitute them in the inequality. Then, the condition of $\lambda^{*}>0$ leads to $i>0.09 \tau /(0.3-\beta)$. On the basis of the empirical study of Hein and Schoder (2009) that finds that $\beta=0.14$ and $\tau=0.14$ in the US and that $\beta=0.15$ and $\tau=0.33$ in Germany, a positive $\lambda^{*}$ requires $i>0.07875$ for the US and $i>0.198$ for Germany. Furthermore, as $s_{c}$ gets smaller or $\alpha$ gets larger, a positive $\lambda^{*}$ requires higher interest rates.

Again, consider the case for the stable equilibrium. Provided that $\beta\left(1-s_{c}\right)-\theta h>0$, the effect of the interest rate on the long-run equilibrium debt-capital ratio is given by

$$
\frac{\partial \lambda^{*}}{\partial i}=\frac{h(\alpha+\tau h)}{i^{2}\left[\beta\left(1-s_{c}\right)-\theta h\right]}>0 .
$$

Equation (13) contradicts the statement of Hein (2007, pp. 323-324) that an increase in the interest rate can either raise or reduce the debt-capital ratio.

By substituting Equation (11) in Equation (6), we obtain the long-run equilibrium rate of the capacity utilization $\left(u^{*}\right)$. Differentiating it with respect to $i$ yields

$$
\frac{\partial u^{*}}{\partial i}=\frac{s_{c}\left(1-s_{c}-\theta\right)}{\left[\beta\left(1-s_{c}\right)-\theta h\right]} .
$$

The denominator of the RHS of Equation (14) is positive because of the local stability condition. Moreover, based on Footnote 4, its denominator is negative when its numerator is negative, which contradicts the stability condition. Therefore, both the numerator and denominator must be positive, ${ }^{6}$ which leads to the result that an increase in the interest rate raises the rate of capacity utilization in the long run.

${ }^{6}$ As mentioned above, the condition for the positive numerator of the RHS of Equation (14), that is, $1-s_{c}-\theta>0$, implies that the short-run equilibrium is DLCU. As a result, the stable long-run equilibrium can be compatible only with Case (a): the short-run equilibrium is both DLCU and DLG. 
Finally, we obtain the long-run equilibrium rate of capital accumulation $g^{*}=s_{c} i$. From this, we obtain the following result.

Result 3. (Hein, 2007) $A$ rise in the interest rate increases the rate of capital accumulation irrespective of the debt regime.

This result seems strange from the Keynesian perspective that holds that lower interest rates produce higher growth. ${ }^{7}$ Furthermore, capital accumulation in the long run is independent of the profit share, which is contrary to the typical Kaleckian proposition concerning the relation between growth and distribution.

\section{Modified model: the case in which dividends are distributed}

In this section, we explain how some analytical results of Hein (2007) are modified when we take into account the case where firms distribute dividends to capitalists. Assuming $s_{f}<1$ instead of $s_{f}=1$ and using Equations (4) and (5), we obtain the short-run equilibrium rate of capacity utilization.

$$
u=\frac{\alpha+\tau h+\left[s_{f}\left(1-s_{c}\right)-\theta\right] i \lambda}{\sigma h-\beta}, \sigma \equiv s_{f}+s_{c}\left(1-s_{f}\right)>0 .
$$

Hereafter, we consider only the case where the short-run equilibrium is stable, which is equivalent to supposing that $\sigma h-\beta>0$. We immediately find that the short-run equilibrium is DLCU if $s_{f}\left(1-s_{c}\right)-\theta>0$, while it is DBCU if $s_{f}\left(1-s_{c}\right)-\theta<0$.

The short-run capital accumulation is given by

$$
g=A+B \lambda, A \equiv \frac{\sigma h(\alpha+\tau h)}{\sigma h-\beta}>0, B \equiv \frac{\left[\beta s_{f}\left(1-s_{c}\right)-\sigma \theta h\right] i}{\sigma h-\beta} .
$$

The short-run equilibrium is DLG if $\beta s_{f}\left(1-s_{c}\right)-\sigma \theta h>0 \quad(B>0)$ and DBG if $\beta s_{f}\left(1-s_{c}\right)-\sigma \theta h<0 \quad(B<0)$.

We also find, using the same method as in Footnote 4, that the condition for DBCU contradicts the condition for DLG. Therefore, as in Hein (2007), there exist

${ }^{7}$ In addition, $g^{*}=s_{c} i$ denies the paradox of thrift that implies that an increase in the savings propensity of capitalists leads to a decrease in the rate of capital accumulation. 
three cases of debt regimes.

Case 1: the short-run equilibrium is both DLCU and DLG. ${ }^{8}$

Case 2: the short-run equilibrium is both DBCU and DBG.

Case 3: the short-run equilibrium is both DLCU and DBG.

Firms' loans are given by the following equation.

$$
\frac{\dot{L}}{p K}=\frac{I}{K}-s_{f}(h u-i \lambda)=s_{c}\left[\left(1-s_{f}\right)(h u-i \lambda)+i \lambda\right] .
$$

Substituting Equations (16) and (17) in Equation (8) and rearranging, we obtain the dynamical equation of the debt-capital ratio for the case where the retention ratio is below unity.

$$
\begin{aligned}
& \dot{\lambda} \equiv G(\lambda ; i)=\left(1-\frac{s_{f}}{\sigma}-\lambda\right) g+\frac{s_{c} s_{f}}{\sigma} i \lambda \\
& =\frac{s_{c}\left(1-s_{f}\right) A}{\sigma}+\left[\frac{s_{c}\left(1-s_{f}\right) B}{\sigma}-A+\frac{s_{c} s_{f} i}{\sigma}\right] \lambda-B \lambda^{2}
\end{aligned}
$$

Needless to say, substituting $s_{f}=1$ in Equation (18) yields Equation (10): our modified model boils down to Hein's (2007) model.

\subsection{Stability analysis in the long run: The DLG case}

We here assume that $B>0$. This corresponds to Case 1: the short-run equilibrium is both DLCU and DLG. Then, the RHS of Equation (18) shows a parabola with its vertex oriented upwards in the $(\dot{\lambda}, \lambda)$ plane. The inflexion axis of the curve is given by

$$
\bar{\lambda}=\frac{s_{c}\left(1-s_{f}\right) B-\sigma A+s_{c} s_{f} i}{2 \sigma B} .
$$

If we assume that $s_{f}=1$, the parabola passes through the origin of the plane, which is identified with Hein (2007). Otherwise, an intercept of the parabola is inevitably positive.

Figure 1 shows the case where $0<s_{f}<1$ and $\bar{\lambda}>0$; this case corresponds to

8 Case 1 is divided into Case 1-1 and Case 1-2 in the following analysis. 
Case 1-1 of Table 1 in the next section. Figure 2 shows the case where $0<s_{f}<1$ and $\bar{\lambda}<0$; this case implies Case 1-2 of Table 1. Figure 3 shows the special case where $s_{f}=1$ and $\bar{\lambda}>0 .{ }^{9}$ From Figures 1 and 2 , we can immediately understand that when the retention rate is lower than unity, Equation (18) always intersects the horizontal axis once within $\lambda>0$ regardless of the sign of the inflexion axis. This result is important because the equilibrium debt-capital ratio is always positive under the DLG regime without any particular condition for the interest rate, which we impose in Section 2.2. Once again, the inflexion axis must be positive in the case of $s_{f}=1$ for the positive equilibrium value (Figure 3). In other words, the interest rate must be high enough to satisfy $s_{c} i(h-\beta)-h(\alpha+\tau h)>0$.

Proposition 1. The long-run equilibrium is stable if the short-run equilibrium is $D L G$. Moreover, to obtain a positive debt-capital ratio in the long-run equilibrium, extremely high interest rates are not needed.

We represent the long-run equilibrium debt-capital ratio $\left(\lambda^{*}\right)$ in Figure 1. Even if an external shock moves the debt-capital ratio to the point $\lambda_{0}$ on the horizontal axis, this ratio continues to decrease in the range of $\dot{\lambda}<0$ until it converges to the equilibrium. In contrast, even if the debt-capital ratio happens to be below its equilibrium, this ratio continues to increase because of $\dot{\lambda}>0$ and finally converges to the equilibrium. This reasoning explains why a unique positive equilibrium under the debt regime is always locally stable.

(Figures 1, 2, and 3 to be inserted here)

\subsection{Stability analysis in the long run: the DBG case}

Next, we consider the case where $B<0$, which means that the short-run equilibrium

${ }^{9}$ We exclude the case where $s_{f}=1$ and $\bar{\lambda}<0$ because this case does not have a positive equilibrium value. For the same reason, we also abstract this case under the DBG regime. 
is DBG (either Case 2 or 3). In this case, the RHS of Equation (18) depicts a parabola with its vertex oriented downwards in the $(\dot{\lambda}, \lambda)$ plane. The necessary and sufficient condition for the existence of the positive equilibrium value, which is equivalent to the condition that the curve crosses the horizontal axis, is that the discriminant of $G(\lambda ; i)=0$ is positive. However, it is difficult to specify this condition because our $0<s_{f}<1$ assumption requires very complicated calculations. Here, we assume that the discriminant is positive. ${ }^{10}$

Figure 4 shows the case where $0<s_{f}<1$ and $\bar{\lambda}>0$; Figure 4 corresponds to either Case 2 or Case 3 in Table 1. Figure 5 shows the case where $0<s_{f}<1$ and $\bar{\lambda}<0$, while Figure 6 shows the special case where $s_{f}=1$ and $\bar{\lambda}>0$. There exists at least one positive equilibrium debt-capital ratio if $\bar{\lambda}>0$, that is, $s_{c}\left(1-s_{f}\right) B-\sigma A+s_{c} s_{f} i<0$ is satisfied (Figures 4 and 6). However, in contrast to Hein (2007), fulfilling this inequality does not require a higher interest rate. This inequality will be satisfied if parameters $\alpha, \tau$, and $h$ are sufficiently large.

Proposition 2. The long-run equilibrium can be stable even if the short-run equilibrium is DBG. Moreover, to obtain a positive debt-capital ratio in the long-run equilibrium, extremely high interest rates are not needed.

Figure 4 shows that the case where $0<s_{f}<1$ and $\bar{\lambda}>0$ has multiple equilibria $\left(\lambda_{1}^{*}, \lambda_{2}^{*}\right)$. The smaller equilibrium, $\lambda_{1}^{*}$, is locally stable, while the larger one, $\lambda_{2}^{*}$, is locally unstable. Once more, there exists a unique positive but unstable equilibrium in the case where $s_{f}=1$, as we mentioned in Section 2. 2 .

(Figures 4, 5, and 6 to be inserted here)

\subsection{The effect of the interest rate on capital accumulation in the long run}

Although our modified model is somewhat complicated, it is possible to investigate the

10 Numerical examples in the next section show the existence of the positive equilibrium under plausible parameter settings. 
effect of the interest rate on the long-run equilibrium. In the following discussion, we consider only the stable and positive equilibrium. The equilibrium in the long run is defined by $\dot{\lambda}=G\left(\lambda^{*} ; i\right)=0$, and its stability condition is given by

$$
\left.\frac{\partial G(\lambda ; i)}{\partial \lambda}\right|_{\lambda=\lambda^{*}}=\left[\frac{s_{c}\left(1-s_{f}\right) B}{\sigma}-A+\frac{s_{c} s_{f} i}{\sigma}\right]-2 B \lambda^{*}<0 .
$$

Note that the stable equilibrium always satisfies Equation (20). Totally differentiating $G\left(\lambda^{*} ; i\right)=0$ yields

$$
\frac{d \lambda^{*}}{d i}=-\left(\frac{\partial G\left(\lambda^{*} ; i\right)}{\partial i}\right) /\left(\frac{\partial G\left(\lambda^{*} ; i\right)}{\partial \lambda^{*}}\right)
$$

where the denominator is negative and $\partial G\left(d^{*} ; i\right) / \partial i$ is given by

$$
\frac{\partial G\left(\lambda^{*} ; i\right)}{\partial i}=\frac{\lambda^{*}}{\sigma}\left\{\frac{\left[s_{c}\left(1-s_{f}\right)-\sigma \lambda^{*} \llbracket \beta s_{f}\left(1-s_{c}\right)-\sigma \theta h\right]+s_{c} s_{f}(\sigma h-\beta)}{\sigma h-\beta}\right\} .
$$

Using $g^{*}$ and $\lambda^{*}$, we can rewrite Equation (18) with $\lambda^{*}=0$ as follows:

$$
g^{*}=\frac{s_{c} s_{f} i \lambda^{*}}{\sigma \lambda^{*}-s_{c}\left(1-s_{f}\right)} .
$$

Equation (23) implies that the positive equilibrium values for the debt-capital ratio and for the rate of capital accumulation impose the condition that $\sigma \lambda^{*}-s_{c}\left(1-s_{f}\right)>0$. We suppose a situation where this inequality is always satisfied. Then, if the short-run equilibrium is DLG (Cases $1-1$ and 1-2), the sign of $\partial G\left(\lambda^{*} ; i\right) / \partial i$ is ambiguous because $\beta s_{f}\left(1-s_{c}\right)-\sigma \theta h>0$, which leads to the ambiguous sign of $d \lambda^{*} / d i$. However, if we consider the situation where the short-run equilibrium is DBG (Cases 2 and 3), we obtain $\partial G\left(\lambda^{*} ; i\right) / \partial i>0$ because $\beta s_{f}\left(1-s_{c}\right)-\sigma \theta h<0$, which leads to $d \lambda^{*} / d i>0$.

Furthermore, differentiating the long-run equilibrium rate of capital accumulation $g^{*}=A+B \lambda^{*}$ with respect to the interest rate yields

$$
\frac{\partial d^{*}}{\partial i}=\frac{\left[\beta s_{f}\left(1-s_{c}\right)-\sigma \theta h\right]}{\sigma h-\beta}\left(\lambda^{*}+i \frac{d \lambda^{*}}{d i}\right) .
$$

Proposition 3. $A$ rise in the interest rate decreases the long-run equilibrium rate of capital accumulation if the short-run equilibrium is $D B G$. 
In the case of $\beta s_{f}\left(1-s_{c}\right)-\sigma \theta h<0$, we obtain $d g^{*} / d i<0$ because $d \lambda^{*} / d i>0$. This result is contrary to the result of Section 2.2. However, in the case of $\beta s_{f}\left(1-s_{c}\right)-\sigma \theta h>0$, this effect is not clear because the sign of $d \lambda^{*} / d i$ is ambiguous.

\section{Numerical examples}

This section presents numerical examples to show that the economically meaningful long-run equilibrium actually exists under plausible parameter settings and that the results of comparative statics analysis differ depending on the circumstances. In this section, we investigate how increases in the interest rate and the profit share affect the long-run equilibrium values of the debt-capital ratio, the rate of capital accumulation, and the rate of profit. Recall that in Hein (2007), the long-run equilibrium value of capital accumulation is given by $g^{*}=s_{c} i$. Therefore, an increase in the interest rate necessarily increases the rate of capital accumulation. In addition, an increase in the profit share never affects the rate of capital accumulation. However, in our model, as will be shown below, an increase in the profit share raises the rate of capital accumulation in some cases and lowers it in others.

From the above analysis, we know that there exist situations where the short-run equilibrium is DLCU or DBCU and DLG or DBG. Note that the combination of DBCU and DLG is impossible. Therefore, four cases - Cases 1-1, 1-2, 2, and 3-are feasible; these are listed in Table 1.

(Table 1 to be inserted here)

Recall that Cases 1-1 and 1-2 correspond to Figures 1 and 2, respectively, and that Cases 2 and 3 correspond to Figure 4. Note that Figure 4 alone cannot distinguish whether the short-run equilibrium is DBCU or DLCU.

We conduct the numerical analysis as follows. First, we find a benchmark for each case. Second, starting from each benchmark, we increase the interest rate (or profit 
share) slightly and then compute the new equilibrium values. When conducting the numerical analysis, we must consider that the short-run equilibrium belongs to the corresponding case even after the interest rate (or profit share) changes. The parameters for each benchmark are listed in Table 2. Naturally, the long-run equilibrium is stable in every case.

(Table 2 to be inserted here)

\subsection{Case 1-1}

Table 3 shows an example that corresponds to Case 1-1. Here, we compute the long-run equilibrium values by increasing the interest rate from 0.1 to 0.1001 and the profit share from 0.3 to 0.301 .

When the interest rate increases, all the long-run equilibrium values increase. This result is similar to the result in Hein (2007). In Hein (2007), for the long-run equilibrium to be stable, the short-run equilibrium must be DLG, which necessarily makes the short-run equilibrium DLCU. In this case, an increase in the interest rate increases all long-run equilibrium values.

When the profit share increases, the debt-capital ratio also increases. In addition, the rate of capital accumulation decreases, and accordingly, the long-run equilibrium is wage-led growth. Moreover, the rate of capacity utilization decreases, and accordingly, the long-run equilibrium is stagnationist. These two results are typical of the Kaleckian model. ${ }^{11}$ However, the rate of profit increases, that is, we never obtain the paradox of cost in which an increase in the profit share lowers the rate of profit. In this respect, our model is different from the typical Kaleckian model.

(Table 3 to be inserted here)

11 The economy is termed wage-led (profit-led) growth if an increase in the profit share lowers (raises) the rate of capital accumulation. In addition, the economy is called stagnationist (exhilarationist) if an increase in the profit share lowers (raises) the rate of capacity utilization. For more on this issue, see Bhaduri and Marglin (1990) and Blecker (2002). 


\subsection{Case 1-2}

Table 4 shows an example that corresponds to Case 1-2. Here, we compute the long-run equilibrium values by increasing the interest rate from 0.02 to 0.0201 and the profit share from 0.4 to 0.401 . Note that in this case, the rate of interest is small compared to the rate in Case 1-1.

The effects of a rise in the interest rate on the long-run equilibrium values are the same as those in Case 1-1; that is, all equilibrium values increase. The result that when the interest rate increases, the rates of capital accumulation and capacity utilization increase seems to be paradoxical. In the usual post-Keynesian theory, an increase in the interest rate is expected to have a negative effect on output and output growth.

The effects of a rise in the profit share are the same as in Case 1-1, except for the effect on the rate of profit. When the profit share increases, the rate of profit decreases, implying the paradox of cost.

(Table 4 to be inserted here)

\subsection{Case 2}

Table 5 shows an example that corresponds to Case 2. Here, we compute the long-run equilibrium values by increasing the interest rate from 0.02 to 0.0202 and the profit share from 0.4 to $0.401 .^{12}$

When the interest rate increases, the debt-capital ratio also increases, but the rate of capital accumulation, the rate of capacity utilization, and the rate of profit decrease. The case in which a rise in the interest rate leads to a decline in the rates of capital accumulation and capacity utilization is considered to be a normal case.

When the profit share increases, the debt-capital ratio decreases. In Cases 1-1 and 1-2 where the short-run equilibrium is DLG, the debt-capital ratio increases as a result of a rise in the profit share. Therefore, in Case 2, the result we obtain is opposite to the

12 To clearly discern the changes in the equilibrium values, we use 0.0202 instead of 0.0201 . 
results in Cases 1-1 and 1-2. In Case 2, the rate of capital accumulation increases, which means that the long-run equilibrium is profit-led growth. Considering that we have wage-led growth in Cases 1-1 and 1-2 where the short-run equilibrium is DLG, we might say that there is a relationship between DLG and wage-led growth and that there is a relationship between DBG and profit-led growth. However, note that this inference is based on numerical examples and not on rigorous analytical solutions. In Case 2, the rate of capacity utilization decreases, implying that the long-run equilibrium is stagnationist, which is the same as in Cases 1-1 and 1-2. A rise in the profit share increases the rate of profit. Consequently, we never obtain the paradox of cost.

(Table 5 to be inserted here)

\subsection{Case 3}

Table 6 shows an example that corresponds to Case 3. Here, we compute the long-run equilibrium values by increasing the interest rate from 0.02 to 0.0201 and the profit share from 0.4 to 0.401 .

When the interest rate increases, the debt-capital ratio, the rate of capacity utilization, and the rate of profit increase, whereas the rate of capital accumulation decreases.

The effects of a rise in the profit share are the same as in Case 2.

(Table 6 to be inserted here)

\section{Conclusions}

Recent Kaleckian studies, taking into account firms' debt accumulation, analyze how the stability condition and the long-run effect of the interest rate on the real economy differ according to debt regime (debt-led or debt-burdened). Hein (2007), one of the representatives among those research works, abstracts the distribution of dividends to capitalists and assumes that the retention ratio is equal to unity. However, this assumption leads to the following extreme results. First, the long-run equilibrium 
debt-capital ratio is stable only if the short-run equilibrium is debt-led growth. Second, the positive equilibrium debt-capital ratio under a debt-led growth regime requires an extremely high interest rate. Third, an increase in the interest rate always raises capital accumulation in the long run, while the income distribution never affects capital accumulation.

This paper investigates the stability condition and the long-run effect of the interest rate when firms distribute dividends to financial capitalists, that is, when the retention rate is lower than unity. Our results are summarized as follows.

The long-run positive equilibrium debt-capital ratio can be stable not only under the debt-led growth regime but also under the debt-burdened growth regime. Regardless of the debt regime, this equilibrium does not impose any special condition on the size of the interest rate. In addition, if the short-run equilibrium rate of capital accumulation is debt-burdened, an increase in the interest rate reduces the equilibrium rate of capital accumulation in the long run. Although the long-run effect of the interest rate on capital accumulation under the debt-led regime is ambiguous, our numerical examples using plausible parameters show that this effect seems to be positive. Furthermore, the numerical examples show that a rise in the profit share decreases long-run capital accumulation under the debt-led growth regime, while it increases long-run capital accumulation under the debt-burdened regime. The paradoxical effect of income distribution on economic growth (that is, wage-led growth à la Kalecki) seems to correspond to the puzzling relation between debt accumulation and economic growth, that is, debt-led growth. These conclusions teach us that setting the retention rate to unity for the sake of simplicity, unlike the "zero saving propensity hypothesis of workers," produces biased analytical results. Therefore, we must pay due attention to this assumption when we construct a theoretical model. 


\section{References}

Asada, T. (2006) "Stabilization policy in a Keynes-Goodwin model with debt accumulation," Structural Change and Economic Dynamics, Vol. 17 (4), pp. 466-485.

Bhaduri, A. and S. Marglin (1990) "Unemployment and the real wage: the economic basis for contesting political ideologies," Cambridge Journal of Economics, Vol. 14, pp. 375-393.

Blecker, R. A. (2002) "Distribution, demand and growth in neo-Kaleckian macro-models," in Setterfield, M. (ed.) The Economics of Demand-led Growth, Challenging the Supply-side Vision of the Long Run, Cheltenham: Edward Elgar.

Charles, S. (2008a) "Corporate debt, variable retention rate and the appearance of financial fragility," Cambridge Journal of Economics, Vol. 32 (5), pp. 781-795.

Charles, S. (2008b) “A post-Keynesian model of accumulation with a Minskyan financial structure," Review of Political Economy, Vol. 20 (3), pp. 319-331.

Charles, S. (2008c) “Teaching Minsky’s financial instability hypothesis: a manageable suggestion," Journal of Post Keynesian Economics, Vol. 31 (1), pp. 125-138.

Charles, S. (2010) 'Explaining persistent cycles in a short-run context: firms' propensity to invest and omnipotent shareholders," Journal of Post Keynesian Economics, Vol. 32 (3), pp. 409-425.

Dutt, A. K. and E. J. Amadeo (1993) "A post-Keynesian theory of growth, interest, and money," in Baranzini M. and J. Harcourt (eds.) The Dynamics of the Wealth of Nations: Growth, Distribution and Structural Change, New York: Macmillan.

Fontana, G. (2009) Money, Uncertainty and Time, Abingdon: Routledge.

Hein, E. (2006) "Interest, debt and capital accumulation: a Kaleckian approach," International Review of Applied Economics, 20 (3), pp. 337-352.

Hein, E. (2007) "Interest rate, debt, distribution and capital accumulation in a post Kaleckian model," Metroeconomica, Vol. 56 (2), pp. 310-339.

Hein, E. (2010) "Shareholder value orientation, distribution and growth-short- and medium-run effects in a Kaleckian model," Metroeconomica, forthcoming.

Hein, E. and C. Schoder (2009) "Interest rates, distribution and capital accumulation-a 
post-Kaleckian perspective on the US and Germany," Institute for International Political Economy Working Paper No. 7/2010.

Hein, E. and T. van Treeck (2010) "Financialisation and rising shareholder power in Kaleckian/post-Kaleckian models of distribution and growth," Review of Political Economy, Vol. 22 (2), pp. 205-233.

Lavoie, M. (1995) "Interest rates in post-Keynesian models of growth and distribution," Metroeconomica, Vol. 46 (2), pp. 146-177.

Lavoie, M. and W. Godley (2001-2) "Kaleckian models of growth in a coherent stock-flow monetary framework: a Kaldorian view," Journal of Post Keynesian Economics, Vol. 24 (2), pp. 277-312.

Lavoie, M. and M. Seccareccia (2001) “Minsky's financial fragility hypothesis: a missing macroeconomic link," in Bellofiore, R. and P. Ferri (eds.) Financial Fragility and Investment in the Capitalist Economy: The Economic Legacy of Hyman Minsky, Volume II, Cheltenham: Edward Elgar.

Lima, G. T. and Meirelles, A. J. A. (2007) "Macrodynamics of debt regimes, financial instability and growth," Cambridge Journal of Economics, Vol. 31 (4), pp. 563-580.

Marglin, S. and Bhaduri, A. (1990) "Profit- squeeze and Keynesian theory," in Marglin, S. and J. Schor (eds.) The Golden Age of Capitalism: Reinterpreting the Postwar Experience, Oxford: Clarendon Press.

Moore, B. J. (1988) Horizontalists and Verticalists: The Macroeconomics of Credit Money, Cambridge: Cambridge University Press.

Rochon, L. P. (1999) Credit, Money and Production: An Alternative Post-Keynesian Approach, Cheltenham: Edward Elgar.

Setterfield, M. (2009) "Macroeconomics without the LM curve: an alternative view," Cambridge Journal of Economics, Vol. 33 (2), pp. 273-293.

Taylor, L. (2004) Reconstructing Macroeconomics: Structuralist Proposals and Critiques of the Mainstream, Massachusetts: Harvard University Press.

Taylor, L. and C. R. V. Arnim (2008) "Debt-equity cycles in the twentieth century: empirical evidence and a dynamic Keynesian model," in Flaschel, P. and M. 
Landesmann (eds.) Mathematical Economics and the Dynamics of Capitalism: Goodwin's Legacy Continued, Abingdon: Routledge. 


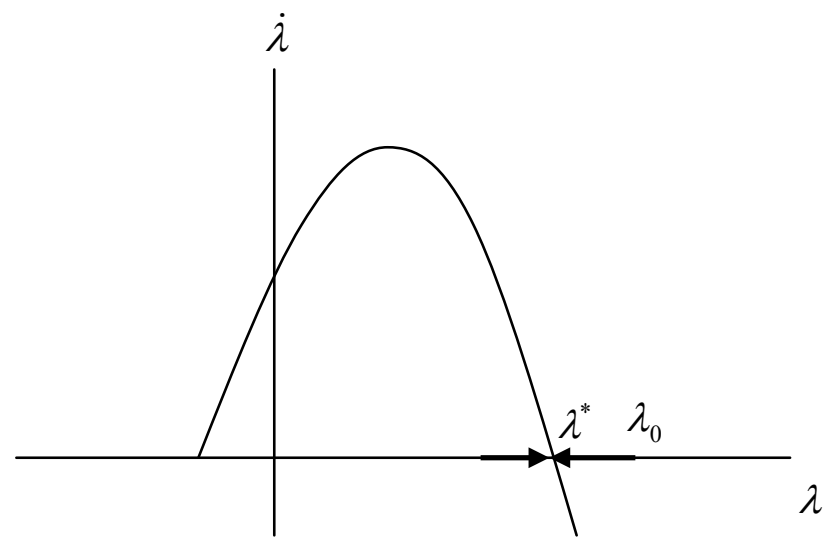

Figure 1: $0<s_{f}<1$ and $\bar{\lambda}>0$ under the debt-led case

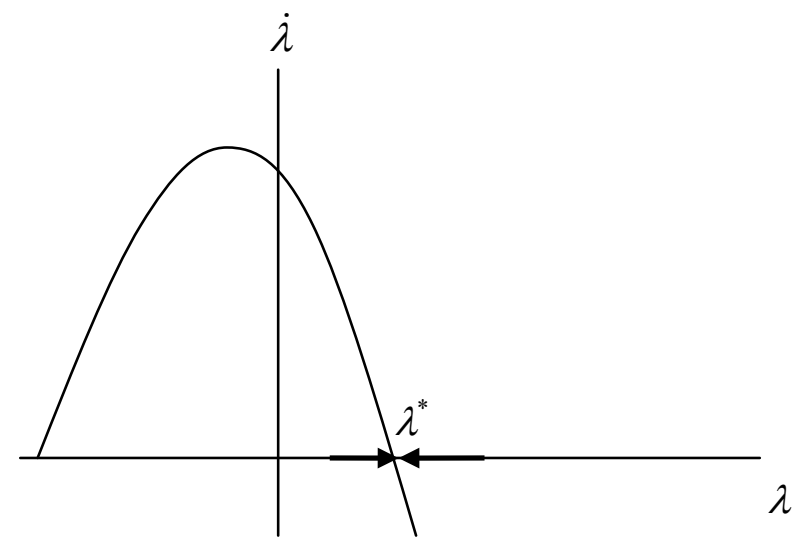

Figure 2: $0<s_{f}<1$ and $\bar{\lambda}<0$ under the debt-led case

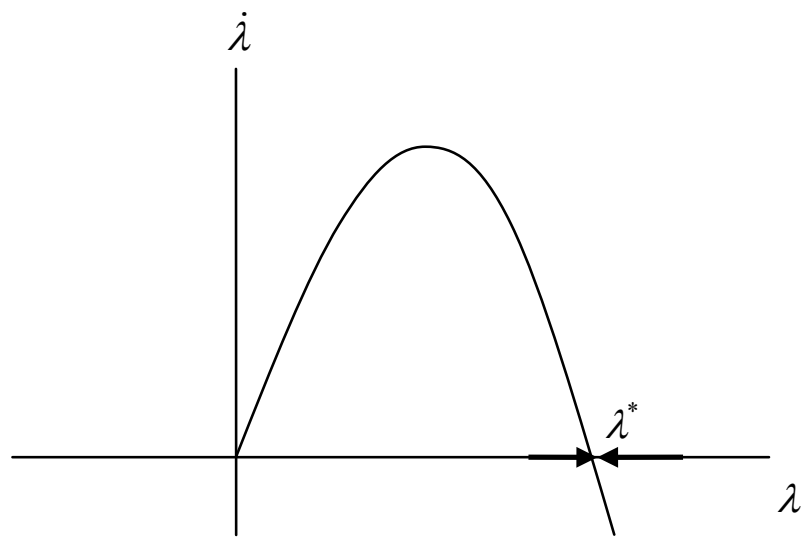

Figure 3: $s_{f}=1$ and $\bar{\lambda}>0$ under the debt-led case 


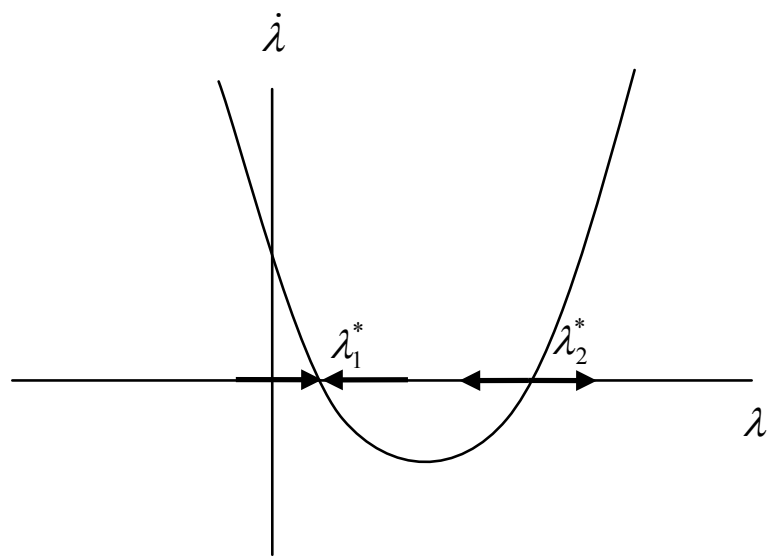

Figure 4: $0<s_{f}<1$ and $\bar{\lambda}>0$ under the debt-burdened case

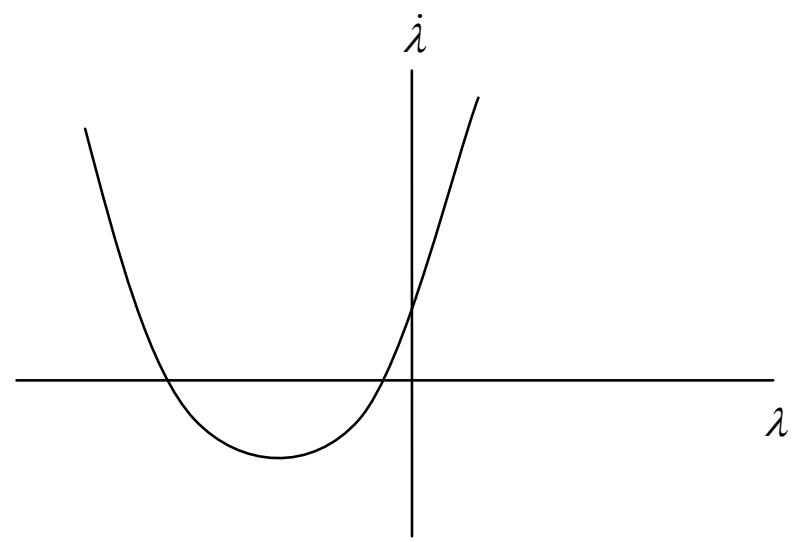

Figure 5: $0<s_{f}<1$ and $\bar{\lambda}<0$ under the debt-burdened case

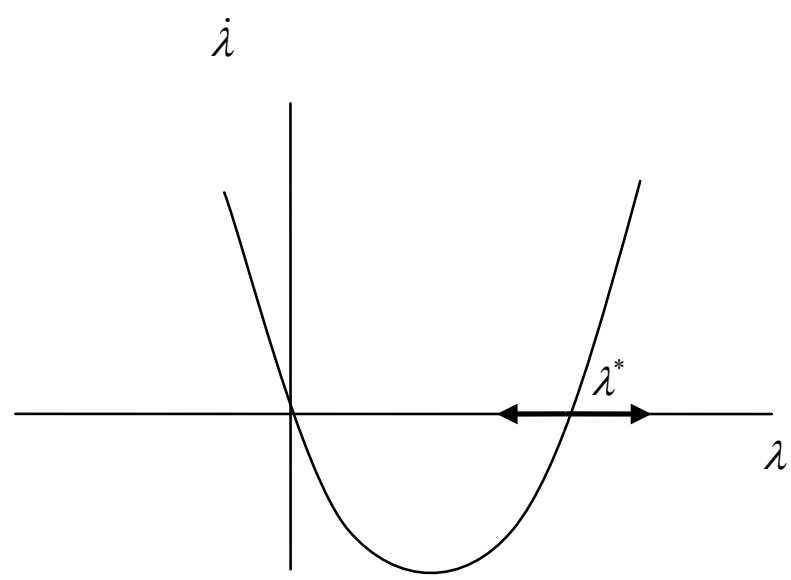

Figure 6: $s_{f}=1$ and $\bar{\lambda}>0$ under the debt-burdened case 
Table 1: Four cases in which the long-run equilibrium is meaningful and stable

\begin{tabular}{cccc}
\hline \hline & Utilization & Accumulation & Shape of parabola \\
\hline Case 1-1 & DL & DL & $\begin{array}{c}\text { Convex upward, } \\
\text { positive axis } \\
\text { Case 1-2 }\end{array}$ \\
& DL & & $\begin{array}{c}\text { Convex upward, } \\
\text { negative axis }\end{array}$ \\
Case 2 & DB & DL & Convex downward, \\
& & DB & positive axis \\
Case 3 & DL & & Convex downward, \\
& & DB & positive axis \\
\hline \hline
\end{tabular}

Table 2: Benchmark parameters for four cases

\begin{tabular}{ccccccccc}
\hline \hline & $s_{c}$ & $s_{f}$ & $h$ & $i$ & $\alpha$ & $\beta$ & $\tau$ & $\theta$ \\
\hline Case 1-1 & 0.7 & 0.98 & 0.3 & 0.1 & 0.05 & 0.05 & 0.02 & 0.025 \\
Case 1-2 & 0.6 & 0.8 & 0.4 & 0.02 & 0.05 & 0.2 & 0.1 & 0.1 \\
Case 2 & 0.6 & 0.7 & 0.4 & 0.02 & 0.05 & 0.1 & 0.1 & 0.3 \\
Case 3 & 0.6 & 0.8 & 0.4 & 0.02 & 0.05 & 0.1 & 0.1 & 0.2 \\
\hline \hline
\end{tabular}

Table 3: Results for Case 1-1

\begin{tabular}{cccc}
\hline \hline & Benchmark & $\begin{array}{c}\text { Rise in interest } \\
\text { rate }\end{array}$ & Rise in profit share \\
\hline Debt-capital ratio & 0.949598 & 0.966359 & 0.959987 \\
Accumulation rate & 0.0700531 & 0.0701049 & 0.0700417 \\
Utilization rate & 0.328542 & 0.330464 & 0.328433 \\
Profit rate & 0.0985627 & 0.0991391 & 0.0988585 \\
\hline \hline
\end{tabular}


Table 4: Results for Case 1-2

\begin{tabular}{cccc}
\hline \hline & Benchmark & $\begin{array}{c}\text { Rise in interest } \\
\text { rate }\end{array}$ & Rise in profit share \\
\hline Debt-capital ratio & 0.137707 & 0.137745 & 0.137722 \\
Accumulation rate & 0.197589 & 0.197591 & 0.19722 \\
Utilization rate & 0.539321 & 0.53934 & 0.536976 \\
Profit rate & 0.215728 & 0.215736 & 0.215327 \\
\hline \hline
\end{tabular}

Table 5: Results for Case 2

\begin{tabular}{cccc}
\hline \hline & Benchmark & $\begin{array}{c}\text { Rise in interest } \\
\text { rate }\end{array}$ & Rise in profit share \\
\hline Debt-capital ratio & 0.221552 & 0.221739 & 0.22155 \\
Accumulation rate & 0.12435 & 0.124335 & 0.124365 \\
Utilization rate & 0.356791 & 0.356787 & 0.355945 \\
Profit rate & 0.142716 & 0.142715 & 0.142734 \\
\hline \hline
\end{tabular}

Table 6: Results for Case 3

\begin{tabular}{cccc}
\hline \hline & Benchmark & $\begin{array}{c}\text { Rise in interest } \\
\text { rate }\end{array}$ & Rise in profit share \\
\hline Debt-capital ratio & 0.142511 & 0.142577 & 0.142509 \\
Accumulation rate & 0.12314 & 0.123137 & 0.123162 \\
Utilization rate & 0.337097 & 0.337104 & 0.336316 \\
Profit rate & 0.134839 & 0.134842 & 0.134863 \\
\hline \hline
\end{tabular}

